\title{
POSITION
}

\section{DATABESKYTTELSE OG DEN ANTROPOLOGISKE EXCEPTIONALISME}

\author{
KRISTOFFER ALBRIS
}

For udenforstående må etiske diskussioner inden for antropologiens verden fremstå besynderlige. På den ene side har antropologer gennem tiden været ekstremt hårde $\mathrm{i}$ deres domme over fagets problematiske historie $\mathrm{i}$ forhold til racespørgsmål, kolonialisme og repræsentationen af ikke-vestlige lande som tilbagestående (Asad 1973). Ligeså har der til tider været rødglødende debatter om de etiske implikationer af antropologens positionering (Agar 1996) for ikke at tale om spørgsmål vedrørende repræsentationen af andre kulturers forståelser af tid, kosmologi og virkelighed (Clifford \& Marcus 1986; Fabian 1983; West 2007) samt løbende diskussioner om antropologers etiske pligt til at tale ,sandhed til magt" (Scheper-Hughes 1995).

På den anden side har antropologer været skeptiske over for indførelsen af standardiserede etiske regelsæt for forskning (Pels 1999), som stadig i dag ses som en trussel mod selve kernen af etnografisk arbejde: de mellemmenneskelige relationer, som antropologer indgår i under feltarbejdet. På trods af dette er der i dag en række retningslinjer fra nationale og internationale faglige associationer, der udstikker relativt fleksible rammer for forskningspraksis. Det er dog værd at huske på, at de nuværende etiske retningslinjer fra American Anthropological Association (AAA 2012) først kom i 1971 (de foregående fra 1948 var en kort udtalelse), hvorefter de først fandt form som omfattende retningslinjer i 1998 og kun er vejledende i den forstand, at de anfører nogle overordnede principper for god etisk praksis (se Fluehr-Lobban 2014).

Denne modstilling behøver naturligvis ikke at blive set som et paradoks. Tværtimod. Ét er at behandle sine informanter, interlokutører eller forskningsdeltagere med respekt og at behandle feltnoter, interviews og andet feltmateriale forsvarligt. Noget andet er at underlægge sig regulerende regimers bureaukratiske måder at håndtere og bedømme etiske principper på i planlægningen og udførelsen af antropologisk forskning. For antropologien giver en sådan positionering mel- 
lem en høj etisk overligger og en modvilje mod en vandtæt standardisering af etisk forskningspraksis dog kun mening set $\mathrm{i}$ lyset af, at der igennem årene er opbygget en selvforståelse af faget som værende unikt. En selvforståelse, som jeg i det følgende vil referere til som den antropologiske exceptionalisme. Essensen af denne exceptionalisme er, at antropologer tænker deres egen forskningspraksis som grundlæggende forskellig fra anden vidensproduktion, idet den antropologiske viden skabes relationelt og derfor ikke ejes fuldt ud af hverken antropologen, informanten eller andre. Hertil skal lægges, at det antropologiske arbejde er kontingent, eksplorativt og ikke-deterministisk, og at det for eksempel ikke altid er muligt at indhente informeret samtykke fra informanter. Et punkt, jeg vil vende tilbage til.

Når det er relevant at rejse denne debat, skyldes det, at databeskyttelse er et af de mest presserende emner i verden i dag, i takt med at reguleringen af internettet og Big Tech-firmaers overvågning af almindelige borgere er blevet en betændt politisk sag. Den politiske og juridiske regulering af data, sociale medier og digitale teknologier har også stor betydning for forskning og videnskab, herunder antropologien. Spørgsmålet er imidlertid, om disse generelle tendenser mod en øget bekymring om databeskyttelse udfordrer antropologiens modvilje mod at standardisere etik i forskningen.

Mit formål med denne position er at gennemgå en række nyligt publicerede udtalelser og artikler fra antropologer om data og dataetik og endvidere at diskutere, hvorfor og hvordan antropologien som fag kan have en pragmatisk tilgang til de nye tendenser og politiske vinde vedrørende databeskyttelse.

\section{Fra etik til databeskyttelse - et nybrud?}

Elefanten i rummet er naturligvis vedtagelsen af den nye EU-persondataforordning (GDPR). I årene op til og i kølvandet på GDPR har en række udgivelser af antropologer set dagens lys. De vidner om, at debatten om antropologisk forskningsetik er gået ind i en ny fase. Hvor debatterne om etik traditionelt set mest har handlet om repræsentation, diskurser og antropologiens eksotificering af Den Anden, handler det nu om, hvad data er, og hvordan data skal behandles etisk forsvarligt. For nogle antropologer virker det umiddelbart, som om GDPR udgør en trussel mod hele forskningstraditionens eksistens. For eksempel spørger en antropolog i et blogindlæg, der handler om konsekvenserne af GDPR (Humphries 2018), om antropologi overhovedet stadig er lovligt.

Bekymringen går dog langt ud over GDPR og persondatalovgivning. Den retter sig også mod en stigende tendens til, at etiske komiteer og udvalg overvåger forskningspraksis, hvilket kan have en ensrettende effekt, da tilgangen ofte mod- 
elleres over biomedicinske måder at forholde sig etisk på til testsubjekter. En af konsekvenserne af dette er, at feltnoter for eksempel kan blive genstand for minutiøs granskning af etiske komiteer og udvalg, hvilket udfordrer selve ideen om den antropologiske forskning som værende eksplorativ og derfor fejlbarlig (Mosse 2006). Samtidig udfordrer det ideen om, hvem der ejer data, og hvad antropologiske data i grunden er for en størrelse (Pels 2018:393).

Den europæiske antropologforening EASA udsendte i 2018 en officiel anbefaling til antropologer om, hvordan man skal forholde sig til databeskyttelse og datahåndtering set i lyset af den øgede opmærksomhed og nye lovgivning på området. Anbefalingen baserer sig på en udtalelse udsendt af en forskergruppe ved Leiden University i Holland (Boog et al. 2018), ledet af Peter Pels og kolleger. I forbindelse med denne udtalelse er der publiceret flere artikler, der forsøger at udbrede positionerne og argumenterne i forhold til databeskyttelse set fra et antropologisk perspektiv. De samme argumenter, som EASA-udtalelsen oplister, kan derfor findes i flere artikler i en forumdiskussion i tidsskriftet Social Anthropology (Boog et al. 2018; Pels 2018) samt i andre tidsskriftsartikler (Dilger et al. 2018).

I en artikel, der bygger på udtalelsen fra Leiden University, rejser Peter Pels (Pels 2018:391) spørgsmålet, om, hvorvidt datahåndtering og databeskyttelse varsler en ny epoke inden for etiske diskussioner i antropologien, eller om det blot er en fortsættelse af tiltagende grader af bureaukratiske styringsregimers kontrol med forskning (Strathern 2000). Spørgsmålet er vigtigt i den forstand, at det for antropologien som disciplin endnu ikke står klart, hvorvidt databeskyttelse i forhold til informanter og forskningsdeltagere, som det specificeres i GDPR, kan ske i overensstemmelse med fagets kerneværdier. Disse, som Pels opstiller, er blandt andet, at ejerskab af antropologisk data ikke kan fastsættes ud fra gældende ideer om dataejerskab, da data produceres og frembringes kollektivt mellem forsker og informanter (Pels 2018:393). Da produktionen af data herudover forudsætter tillidsfulde relationer skabt undervejs i feltarbejdet, er det problematisk at tale om data som én bestemt ting, som GDPR og såkaldte etiske regimer kræver. Fra det antropologiske perspektiv vil data betyde forskellige ting for forskellige mennesker, og derfor bør faget være skeptisk over for standardiseringer af ideen om data (op.cit. 396).

Disse perspektiver går igen i EASA-udtalelsen, der som nævnt baserer sig på forarbejdet lavet af Pels og hans kolleger fra Leiden (Boog et al. 2018). Udtalelsen oplister seks principper for antropologisk forskning (i denne kontekst mere eller mindre synonymt med etnografisk feltarbejde baseret på deltagerobservation, uden at dette dog gøres eksplicit). Det er værd at nævne, hvad hver af disse omhandler: 1. Ejerskab: Etnografiske materialer og data samproduceres af forskere 
og forskningsdeltagere; 2. Arkivering: I etnografisk forskning er „data“ altid en del af et socialt forhold; 3. Samtykke: Etnografisk deltagelse i et socialt miljø kan føre til situationer og dynamikker, som ikke altid kan kontrolleres af forskeren, og hvor det ikke altid er muligt (ja, ofte umuligt) at opnå forudgående informeret samtykke; 4. Forvaltning: Forskere har et videnskabeligt og etisk ansvar for at bevare og beskytte integriteten af etnografiske materialer og data; 5. Embargo: Forskere har en særlig pligt til at overveje at kontrollere tredjeparts adgang til etnografiske materialer; 6. Offentlig adgang og deling: Etnografisk forskning medvirker til, at etnografer har en særlig pligt til at overveje anmodninger fra forskningsdeltagere (eller deres efterkommere) om at dele materialer, medmindre dette vil påføre unødig skade af enhver art.

Disse principper for håndtering af etnografisk materiale og udførelsen af feltarbejde i en post-GDPR- og databeskyttelsessensitiv verden er utvivlsomt af allerstørste vigtighed. De færreste antropologer og etnografer vil sandsynligvis opponere, da de selvsamme værdier har været med til at forme den moderne version af faget, som vi kender det i dag. Problemet er dog, at GDPR - og de nationale lovgivninger, der er blevet vedtaget for at implementere GDPR - netop er sat i verden for at sikre EU-borgernes rettigheder i forhold til de grundlæggende principper nedfældet i forordningens artikel 5: at personoplysninger skal behandles lovligt, rimeligt og på en gennemsigtig måde (EU 2016:95). Derfor er der ikke frihed for forskere på alle hylder. Vi kan være imod bureaukratiseringsmaskinens måde at implementere databeskyttelsen på, men ikke de grundlæggende principper. Ikke mindst fordi disse rettigheder bør være i antropologers interesse at forsvare, af såvel de politiske overbevisninger, som størstedelen af antropologer har, som af hensyn til vores informanters lovmæssige rettigheder.

Uagtet at der er stærke kræfter, der ønsker at modstå enhver form for udefrakommende krav om ændringer af antropologers praksis, må antropologien som videnskabeligt fælleskab være pragmatisk indstillet over for at tolke GDPR-reglerne på en sådan måde, at der sikres overensstemmelse med loven. Der er ingen vej udenom. Og måske ser fremtiden heller ikke helt så sort ud, som nogen lader til at frygte.

Under GDPR er forskere, herunder antropologer, i realiteten garanteret ret vide rammer for forskningsfrihed, hvilket er specificeret i artikel 85, stk. 1 (EU 2016:190). Som Sleebom-Faulkner og Simpson (2018:403) pointerer, er GDPR et væsentligt fremskridt for samfundsvidenskaberne, da GDPR i modsætning til forgængeren DPR (Data Protection Regulation) ikke sidestiller samfundsforskning med medicinsk og naturvidenskabelig forskning, men derimod kunst og journalistik. Dette giver en større grad af frihed i forhold til databeskyttelsesregulering for antropologer, end hvad har været tilfældet hidtil. De foregående ret- 
ningslinjer (DPR) blev dog sjældent fulgt eller skelet til af forskere, og det er velkendt, at dette problem rakte langt ud over den akademiske verden. Det var en af bevæggrundene for overhovedet at vedtage GDPR. Desuden er det vigtigt at pointere, at diskussioner om antropologiens og etnografiens særlige metoder også løbende bliver forsvaret i EU-regi, herunder hvordan disse har særlige behov med hensyn til databeskyttelse og etik mere generelt (Iphofen 2013). Der er altså muligheder for at kunne tilpasse sig GDPR på pragmatisk vis, som vi skal se i det følgende.

\section{Pragmatisme}

Et eksempel på, hvordan man kan gå pragmatisk til værks, kommer fra den spanske antropolog Alberto Corsin Jimenez (2018), som har givet en række anbefalinger til, hvordan antropologer og kvalitative forskere kan tolke GDPR. Denne guide er brugbar, da den går specifikt på de enkelte elementer i GDPR, der har relevans for etnografisk feltarbejde. Diskussionen om informeret samtykke (,informed consent") kan tjene som eksempel.

For et par årtier siden gik debatten om informeret samtykke på, om antropologer overhovedet var for eller imod ideen. Fluehr-Lobban (1994) argumenterede dengang for, at informeret samtykke er kompatibel med antropologisk forskningspraksis, hvis det som udgangspunkt gives verbalt og fortløbende i forskningsprocessen snarere end som en underskrevet kontrakt. Selvom det også i dag rent etisk ville kunne forsvares at udføre antropologisk forskning i visse sammenhænge uden informeret samtykke og endda som undercoverforskning (Sleeboom-Faulkner \& McMurray 2018), forventes antropologer og etnografer efterhånden i videst muligt omfang at oplyse deres informanter om, hvad forskningsprojektet går ud på, hvad det vil føre til, og hvad den indsamlede information eller data skal bruges til.

Som EASA-udtalelsen nævner i punkt 3, er det dog til tider umuligt at sikre selv verbalt samtykke om forskningsdeltagelse, for ikke at tale om skriftligt samtykke. Dette virker umiddelbart som værende i strid med et fundamentalt princip i GDPR, nemlig oplysningspligten. Jimenez påpeger dog, at GDPR flere steder tillader undtagelser fra reglen, så længe der tages forbehold, og formålet med dataindsamlingen er legitimt:

For at imødegå denne udfordring giver artikel 6, stk. 4, mulighed for at behandle data, hvor der ikke er opnået samtykke, så længe behandlingen anses for 'forenelig' (jf. punkt 50). Artikel 6, stk. 1(f), tillader også behandling af data uden samtykke i forhold til den dataansvarliges legitime interesser (i dette tilfælde forskeren) (Jimenez 2018:2, oversat fra engelsk) 
Jimenez' gennemgang af GDPR viser, at der er smuthuller og undtagelser fra de overordnede regler, som gør, at etnografisk forskning kan finde vej til at omgå for eksempel skriftligt samtykke (op.cit.3). Eksemplet med informeret samtykke viser relativt tydeligt, at antropologiens forhold til standardiserede etiske praksisser har været præget af ret så konservative standpunkter, som dog langsomt ændres. Set i det lys virker det ikke skræmmende at skulle forholde sig til GDPR-reglernes ændrede praksis. Især ikke, hvis det sker ud fra en nærlæsning af de muligheder for at bedrive socialvidenskabelig forskning, herunder etnografi, som GDPR har indbygget i sig.

Den store bekymring i de ovenfor refererede artikler, og som rækker ud over bekymringen for GDPR, er det bureaukratiske maskineri og de rigide mekanismer, der sættes i spil for på forhånd at sikre, at forskning udføres etisk. Nogle antropologer vil måske hævde, at ingen er bedre til at beskytte personfølsomme oplysninger om vores informanter end os selv, da vi er uddannet til at håndtere det (Castillo 2018:407). Det er der selvfølgelig en grad af sandhed i. Men denne pointe overser, hvilken verden vi aktuelt lever i. Information om mennesker florerer i mængder og intensiteter, som er radikalt væsensforskellig i forhold til for blot 15 år siden, hvor der ikke fandtes Facebook og e-Boks, for ikke at tale om kunstig intelligens og adfærdsstyrende algoritmer. Selvom antropologer måtte mene, at al etnografisk viden - og derfor også etnografiske data - er relationel, vil det i stigende grad blive svært at navigere med så vage forståelser af, hvad produkterne af etnografisk arbejde er, når databeskyttelse har fået høj politisk prioritet og derfor også institutionaliseres som mere skærpede love i vores stadig mere digitaliserede samfund. Inden for forskning er der også kræfter, der trækker mod åbne principper for datadeling, hvilket inden for antropologien diskuteres af blandt andet Murillo (2018), der spørger, om ikke netop forståelsen af data som værende samproduceret af forskere og informanter bør lede til mere åbenhed i delingen af data. Sådanne tendenser presser også implicit den antropologiske exceptionalistiske forståelse af databeskyttelse, fordi det betyder, at der skal sættes rammer for styringen af, hvor data opbevares, hvordan data deles, og hvordan data må bruges. Rammer, der nødvendigvis må række ud over den enkelte antropologs evne til at håndtere forskningsetiske spørgsmål relationelt og personligt, som mange ellers ser som kernen i feltarbejdets etik (Castillo 2018:407).

\section{Konklusion}

Forskningsetik og god metodisk praksis har altid været et ømtåleligt emne i antropologien, ikke mindst fordi fagets ånd næres af en evigt selvransagende refleksivitet. Som jeg har forsøgt at pointere i denne position, er udgangspunktet for 
antropologer at være skeptiske over for retningslinjer, der sigter mod at beskytte de mennesker, der deltager i antropologisk forskning. Den grundlæggende ide er, at fordi antropologisk viden produceres relationelt, må de etiske og moralske praksisser også funderes relationelt og derfor variere fra kontekst til kontekst. Ideen hviler på, at antropologer som individer er i stand til at kunne agere etisk forsvarligt via deres egen person.

Som antropologer skal vi dog være varsomme med at påkalde os en exceptionalisme, som dybest set afhænger af, at vi har en særlig metode og et særligt syn på verden (teoretisk, analytisk, moralsk, politisk) qua fagets kollektive bevidsthed. Hvis vi ikke er villige til at justere på visse aspekter af antropologisk forskningspraksis, kan der være en reel risiko for, at den nye databeskyttelseslovgivning vil have konsekvenser for individuelle antropologers virke. Det vides dog ikke endnu præcis, hvordan GDPR skal fortolkes, da forordningen er bevidst uklar på en lang række punkter, herunder hvor meget fleksibilitet artikel 85 tillader forskere, journalister og kunstnere. Domsafgørelser i de kommende år vil afgøre, hvor grænserne går.

Uanset om lov ikke er andet end institutionaliseringen af etik og moral, som antropologer ofte vil være de første til at påpege, er lov i en moderne retsstat dog også noget, som antropologer må følge, hvor absurd det end måtte være at skulle pointere det.

\section{Litteratur}

AAA

2012 Principles of Professional Responsibility. American Anthropological Association. http://ethics.americananthro.org/category/statement/.

Agar, Michael

1996 The Professional Stranger. An Informal Introduction to Ethnography. San Diego: Academic Press.

Asad, Talal

1973 Anthropology and the Colonial Encounter. London: Ithaca Press.

Boog, Igor, J. Henrike Florusbosch, Zane Kripe, Tessa Minter, Peter Pels \& Metje Postma 2018 Data Management for Anthropologists and Ethnographers. A Position Paper. Forum discussion. Social Anthropology/Anthropologie sociale 26(3):397-402.

Castillo, Rosa

2018 Subverting "Formalized" Ethics through Mainstreaming Critical Research Ethics and a Responsive Review Process. Forum discussion. Social Anthropology/ Anthropologie sociale 26(3):406-07.

Clifford, James \& George Marcus

1986 Writing Culture. The Poetics and Politics of Ethnography. Berkeley: University of California Press. 
Dilger, Hansjörg, Peter Pels \& Margaret Sleeboom-Faulkner

$2018 \quad$ Guidelines for Data Management and Scientific Integrity Ethnography.

Ethnography 20(1):3-7.

EASA

2018 EASA's Statement on Data Governance in Ethnographic Projects. European Association for Social Anthropologists. https://www.easaonline.org/downloads/ support/EASA\%20statement\%20on\%20data\%20governance.pdf.

EU

2016 Europa-Parlamentets og Rådets forordning (EU) 2016/679 af 27. april 2016 om beskyttelse af fysiske personer i forbindelse med behandling af personoplysninger og om fri udveksling af sådanne oplysninger og om ophævelse af direktiv 95/ 46/EF (generel forordning om databeskyttelse). Official Journal of the European Union L119:1-88.

Fabian, Johannes

1983 Time and the Other. How Anthropology Makes its Object. New York: Columbia University Press.

Fluehr-Lobban, Carolyn

1994 Informed Consent in Anthropological Research: We are not Exempt. Human Organization 53(1):1-10.

2014 Ethics. In: H. Russell Bernard \& Clarence C. Gravlee (eds): Handbook of Methods in Cultural Anthropology. Second Edition. Lanham: Rowman \& Littlefield Publishers.

Humphries, Rachel

2018 Is Anthropology Still Legal? Notes on the Impact of GDPR. Blog for Institute for Research into Superdiversity (IRiS), University of Birmingham. https: //superdiversity.net/2018/05/16/is-anthropology-legal/.

Iphofen, Ron

2013 Research Ethics in Ethnography/Anthropology, European Commission. http: //ec.europa.eu/research/participants/data/ref/h2020/other/hi/ethics-guide-ethnoganthrop_en.pdf.

Jimeìnez, Alberto Corsín

2018 Data Governance Framework for Ethnography v 1.0. Madrid: CSIC. http:// digital.csic.es/bitstream/10261/172227/3/data\%20governance $\% 20$ framework $\% 201$ 81115.pdf.

Mosse, David

2006 Anti-Social Anthropology? Objectivity, Objection, and the Ethnography of Public Policy and Professional Communities. Journal of the Royal Anthropological Institute 12:935-56.

Murillo, Luis

2018 What Does “Open Data” Mean for Ethnographic Research? American Anthropologist 120(3):577-82.

Pels, Peter

Professions of Duplexity. Current Anthropology 40(2):101-36.

2018 Data Management in Anthropology. The Next Phase in Ethics Governance? Forum discussion. Social Anthropology/Anthropologie sociale 26(3):391-96. 
Scheper-Hughes, Nancy

1995 The Primacy of the Ethical. Propositions for a Militant Anthropology. Current Anthropology 36(3):409-40.

Sleebom-Faulkner, Margaret \& Bob Simpson

2018 Research Ethics and Data Management. Perspectives from the UK. Forum discussion. Social Anthropology/Anthropologie sociale 26(3):402-04.

Sleeboom-Faulkner, Margaret \& James McMurray

2018 The Impact of the New EU GDPR on Ethics Governance and Social Anthropology. Anthropology Today 34 (5):22-23.

Strathern, Marilyn

$2000 \quad$ Audit Culture. Anthropological Studies in Accountability, Ethics and the Academy. London: Routledge.

West, Harry

2007 Ethnographic Sorcery. Chicago: University of Chicago Press. 
